\title{
Intelligent Gauge Control System Using ARM and Fuzzy PI Controller
}

\author{
Tao GONG, Lei QI \\ College of Information Science \& Technology, Donghua University, \\ Shanghai, 201620, China, \\ taogong@dhu.edu.cn
}

\begin{abstract}
The longitudinal strip thickness error is an important problem in the hydraulic cold rolling industries, and the random disturbances may increase this error. To decrease this error, we proposed a new ARM9-based gauge control system, which is better than traditional automatic gauge control (AGC) system. This ARM9-based control system was comprised of an ARM9, three sensors, a fuzzy PI controller and other devices. The traditional AGC system was uncertain to deal with this error because the parameters were adjusted by human operators. This new ARM9-based control system had better chip such as ARM9 and used fuzzy controller to transform the uncertain information about this error into some certain data. Moreover, this new ARM9-based control system can be smaller and easier to carry. The experimental results were made with the Matlab tool, and the data show that this new ARM9-based gauge control system performs better than the traditional AGC system and is more robust than the traditional one against the distances.
\end{abstract}

Keywords: ARM9; fuzzy PI controller; gauge control; error; AGC.

\section{Introduction}

In the hydraulic cold rolling industries, the longitudinal thickness control system of strips is generally named AGC system (Automatic Gauge Control system) [1-10]. The control core of this AGC system is the automatic position control (APC) system of the cylinder. Based on the APC, the device for measuring the gauge is set at the output position, in order to measure the gauge for the output part of the strip. But due to the inertia and the delay, the traditional gauge control caused the longitudinal strip thickness error, which decreased the effectiveness of this control process [11].

As we know, the hydraulic cold rolling mill consists of screw-down system, backup roll, work roll and all kinds of sensors. To generate power, the screw-down system is made up of cylinder, servo valve and the sensors of pressure and position. The pressure sensors are used in the feedback control of pressure. In a similar way, with position sensors, the screwdown system can track the position of the cylinder accurately. Neither position nor pressure control of the screw-down system can be directly used to control the thickness errors of the sheet strips.

In order to control the thickness errors of the sheet strips, the current gauge of sheet strips should be measured and the error signals should be used to correct the actual output of the computer controller. So in the AGC hydraulic computer control system, there are two thickness gauges. One is used for the strip thickness before stand, and the other is for the strip thickness after stand.

Up to now, the traditional PI control has taken a useful role for the gauge control in the hydraulic cold rolling industries, but an increasing number of problems on these errors are challenging this traditional control method. Due to the wrong experience of the operators and some random disturbance to the machine, the ineffective control may cause some damages to the control object and the operators. Recently the electromagnetic disturbance has been tested in decreasing the effectiveness of the AGC system, so a new control system is necessary to adjust the parameters by itself against the disturbance. For example, a control algorithm is proposed with an artificial neural network [12]. In this paper, an intelligent gauge control system is designed on the Advanced RISC Machines (ARM) and some intelligent PI control strategies [13].

\section{Problem on Thickness Errors}

For a classic PI control system in the hydraulic rolling industry, the cylinder position loop of the AGC system plays an important role in improving the quality of sheet strips [11]. Corresponding to the AGC system, the cylinder position loop mentioned ahead is an automatic position control system, which is named APC. In this hydraulic AGC system, the thickness deviation is eliminated by hydraulic screw-down servo system, which consists of cylinder position control system (APC) and rolling force system. 
In this system, it is important to eliminate the thickness errors of sheet strips. In fact, only accurate control strategy can achieve the above objectives. With the development of control theory and control engineering, comprehensive researches have been employed and great accomplishments have been attained. However, neither classic feedback control policies nor modern state-space methods could acquire enough accuracy, because both of them are based on some accurate mathematic models of control plans. Unfortunately, it is difficult to construct accurate models of hydraulic rolling mills because of the complexity. What's more, the nonlinear models hinder the implementation of some traditional control strategies. So it is interesting to try more advanced controllers to solve the severe problems mentioned above. In the next section, the design of gauge controller based on ARM and PI control strategy will be analyzed in details.

\section{Design of ARM-Based Fuzzy PI Control}

The structure of the ARM-based AGC fuzzy PID controller is designed with a modular design strategy. This fuzzy PID controller consists of technological setting module, position signal sampling module, gauge signal sampling module, executing unit, signal processing unit and pressure signal sampling module, and so on [14-23]. In this control system, the module of technological settings sends some command signals, like gauge command, rolling force command, etc. The module of signal processing unit deals with the processing of raw signals sampled from sensors. The module of executing unit sends out control signals to hydraulic servo valves. The modules of pressure signal sampling, position signal sampling and gauge signal sampling just cope with pressure, position and gauge signals respectively.

In order to prompt the anti-interference ability of the ARM-based fuzzy PI controller, several measures have been taken. First, in the power supply of ARM chip, the capacitor improves the circuit of electromagnetic compatibility (EMC) ability. Second, some photoelectric isolation assures that the electrical current cannot feed back to the fragile ARM chip.

As we know, the thickness deviation of sheet strips should be within a range according to actual requirements. The thickness gauge before stand measures the thickness of the input, and the thickness gauge after stand measures the output thickness of sheet strips, as shown in Figure 1.

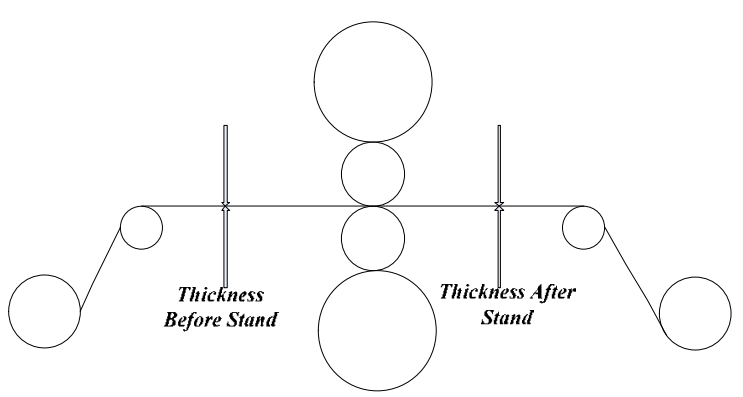

Figure 1. Layout of Thickness Gauges

In Figure 1, the layout of the thickness gauges set on the hydraulic cold rolling mill is clearly depicted. From the input thickness gauge to the output thickness gauge of the hydraulic cold rolling mill, a space distance exists and it is necessary to consider the constant time delay because of the space. Therefore, gauge compensator is designed to eliminate the inherent error, and the controller based on fuzzy strategy combined with conventional PID is shown in Figure 2. As mentioned ahead and described above, the AGC hydraulic control system based on fuzzy PID consists of ACA (compensation element), ATA (Thickness control element), APA (Position Control element), cylinder, roll (backup roll and work roll) and sensors. In the system depicted below in Figure. 2, ACA, ATA and APA are the three components of the gauge controller based on fuzzy PID. In details, ACA is feed-forward adjuster, ATA is the outer loop adjuster, and APA is the inner loop adjuster. Considering that the design of ATA referred to corresponding technology, fuzzy PID algorithm is used to generalized operators' and experts' experience and knowledge to cope with different conditions. Bear in mind that, the PID parameters cannot be self-adjusted in line without the fuzzy logic and inference used herein. As follows, the details of the fuzzy control strategy will be introduced step by step. ACA is the Automatic Compensation Adjuster, ATA is the Automatic Thickness Adjuster, and APA is the Automatic Position Adjuster.

In 1965, L. A. Zadeh addressed the concept of membership function in fuzzy mathematics, and this function has been used widely to describe the fuzzy characters of some things. In this way, the membership function lays a good 


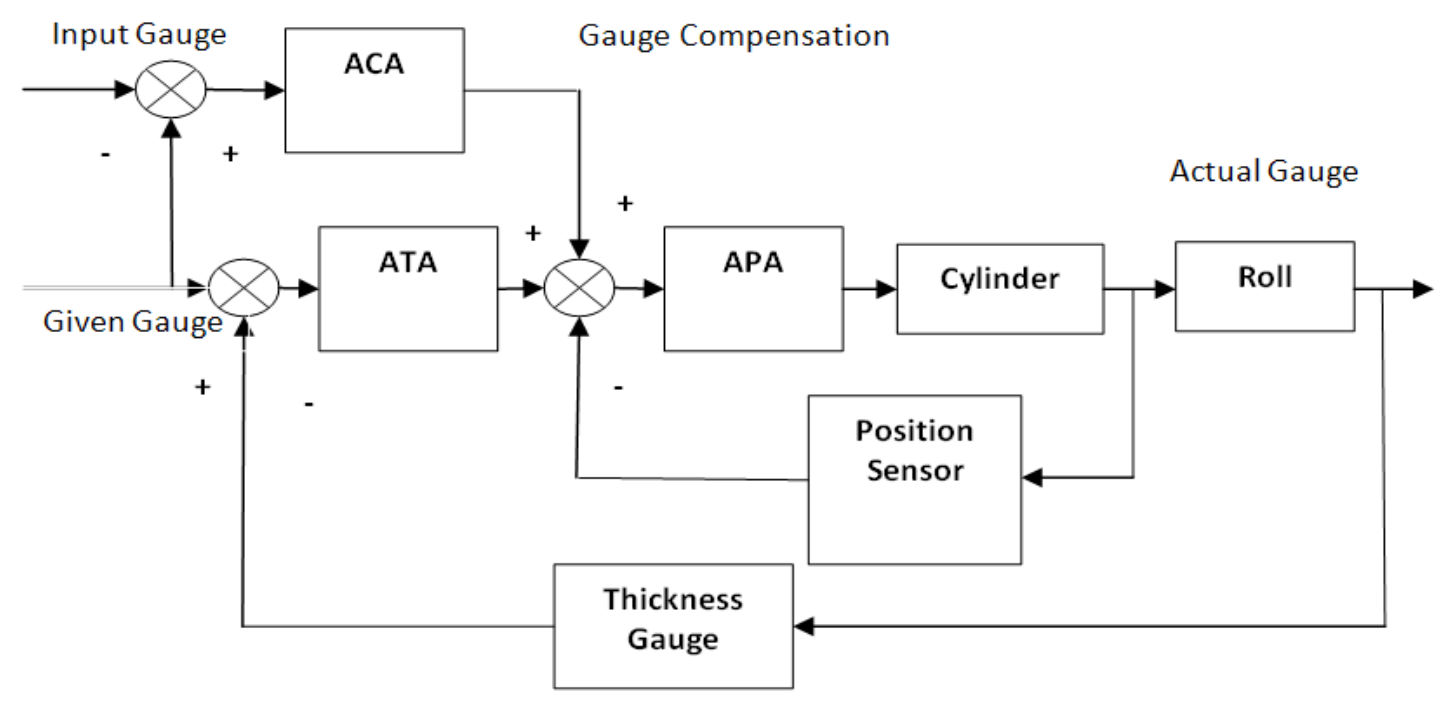

Figure 2. Gauge Controller Based on Fuzzy PID

foundation of fuzzy mathematics. Combined with expert system, the fuzzy control theory comes into being. In essence, the fuzzy control is a kind of computer control methods which just based upon fussy sets, fuzzy linguistic variables and fuzzy inference. Figure 3 gives the basic structure and components of fuzzy control system.
In essence of fuzzy control theory, the PID parameters, $K_{p}, K_{i}$ and $K_{d}$, are the binary functions of $E$ and $E C$, as shown in Figure 4. They can be illustrated respectively below.

$$
\begin{aligned}
& K_{p}=f_{1}(E, E C) \\
& K_{i}=f_{2}(E, E C)
\end{aligned}
$$

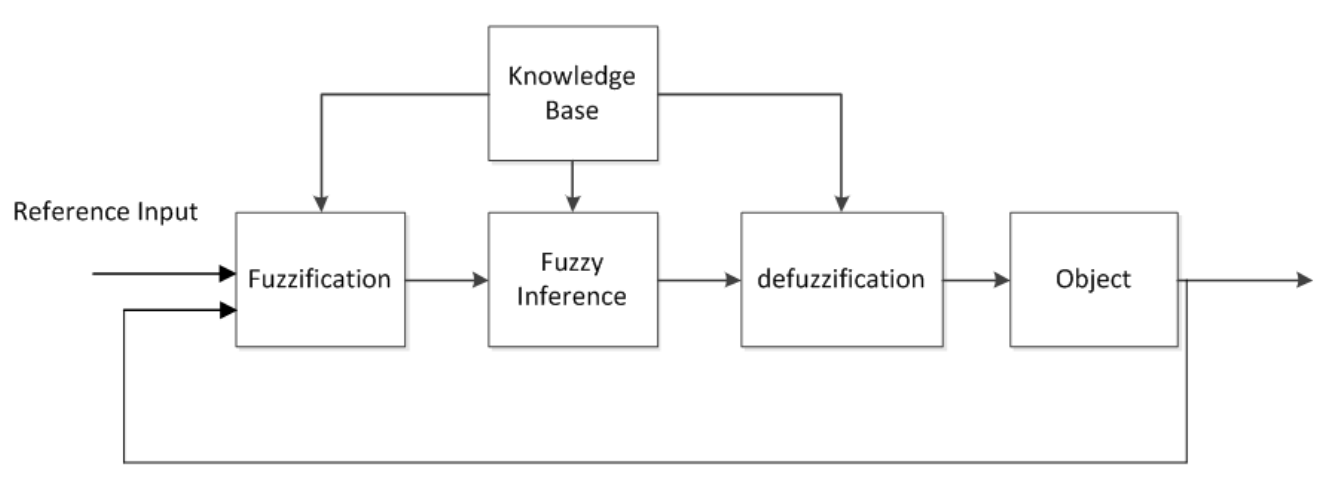

Figure 3. Fuzzy Control System

Now let us get down to the details of fuzzy PID policy. First, the conventional PID control is represented below.

$$
u=K_{p} \bullet E+K_{i} \bullet \sum E+K_{d} \bullet E C
$$

Here, $u$ is the output of PID controller, $E$ is the error signal, EC represents the rate of error signal with time, $\sum E$ is the integration of error signals, $K_{p}$ is proportional constant, $K_{i}$ is the integration constant, and $K_{d}$ is differential constant.

$$
K_{d}=f_{3}(E, E C)
$$

In general, in view of acquiring quick response characters, $K_{p}$ should be bigger and $K_{d}$ should be smaller when the error signal $E$ is bigger. At the same time, $K_{i}$ should be approximately equal zero to avoid system over shoot. As $E$ is neither very big nor very small, $K_{p}$ is assigned a smaller value to eliminate over shoot. With minor error signal $E$, the whole systems 
possess good stability and it's very important to select an appropriate value of $K_{d}$.

Clearly, the fuzzy controller has two linguistic variables, $E$ and $E C$. Now take the error $E$ as an example. For the convenience to discuss, take the absolute value of $E$. Use $|E|$ to represent the absolute value of $E$. Actually, $|E|$ is the absolute value of deviation of sheet strips. The value of $|E|$ is hoped to be within 10 micrometer, or 5 micrometer for the best result. Generally speaking, the deviation of unrefined sheet strips is more than 60 micrometer. Therefore, the universe of fuzzy set of variable $|E|$ is within the range of $[0,60]$.

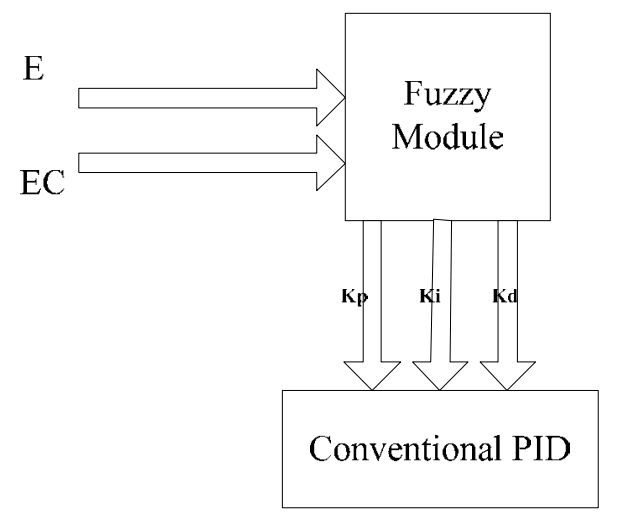

Figure 4. PID Parameters Self-Adjusted with Fuzzy Inference

If the universe of discourse is within the set, $\{0,1,2,3,4,5,6,7,8,9,10,11,12\}$, corresponding to the closed interval $[0,60]$ stated ahead, then the quantized coefficients $k_{\psi}$ follow the formula as follows.

$k_{\psi}=\frac{12}{60}=0.2$

As the universe of discourse stated ahead ( $\{0,1,2,3,4,5,6,7,8,9,10,11,12\})$, according to the fuzzy set theory, it's necessary to select several fuzzy linguistic variables to describe the error signal. In order to attain satisfactory control precision, six variables respectively are EB, VB, LB, SB, AB, and SLB. From EB to $\mathrm{SLB}$, the expression strength is more and more weak. In details, EB is referred to Extremely Big, VB referred to Very Big, LB referred to Largely Big, SB referred to Some Big, AB referred to A Little Big, and SLB referred to Slightly Big.

Actually speaking, the membership function which is relevant to each fuzzy linguistic variable is just a bell ship function as follows. $\mu(\mathrm{x})=e^{-\left(\frac{x-a}{b}\right)^{2}}$

As mentioned above, b equals 16 , and a is assigned different values for different fuzzy linguistic variables. The values of a corresponding to each fuzzy linguistic variable like EB, are stated as follows:

For EB, $\mathrm{a}=1$.

For VB, a $=2$.

For $\mathrm{LB}, \mathrm{a}=4$

For $\mathrm{SB}, \mathrm{a}=6$.

For $\mathrm{AB}, \mathrm{a}=8$.

For SLB, a $=10$.

It is well known that human beings make decisions based on rules. Although we may not aware of it, all the decisions we make are based on computer like if-then statements. Fuzzy machines, which always tend to mimic the behavior of man, work the same way.

In order to realize fuzzy inference, two problems must be solved. First, find an appropriate fuzzy relationship generation algorithm. Second, make the laws of fuzzy inference. Several simple principles are showed below.

if $|E|$ and $|E C|$ then $_{p}$

if $|E|$ and $|E C|$ then $_{i}$.

if $|E|$ and $|E C|$ then $K_{d}$.

Based on the laws stated above, the results of the fuzzy inference are as follows.

$$
\begin{gathered}
K_{p}=\left(\left|E_{1}\right| \times\left|E C_{1}\right|\right) \circ R_{\sim} \\
R_{\sim}=\left(\left|E_{1}\right| \times\left|E C_{1}\right|\right) \circ R_{\sim} \\
K_{d}=\left(\left|E_{1}\right| \times\left|E C_{1}\right|\right) \circ R_{d}
\end{gathered}
$$

Through the fuzzification, we use membership function to describe fuzzy linguistic variables. Based on fuzzy rules, we make fuzzy decisions. At the end, we obtain the actual results through the defuzzification. With inherent nonlinearity of fuzzy logic and fuzzy inference, better control objectives will be attained without an accurate mathematic model of hydraulic cold rolling mill. 


\section{Experimental Results}

First, we built the transfer function of hydraulic screw-down servo system of the cold mill [24], as shown in Figure 5. As we know, the screwdown system consists of servo valve, amplifier and hydraulic cylinder. Figure 5 shows the components of the screw-down system. Here, $V_{g}$ is the given value of roll gap, and $X_{p}$ is the actual position of the hydraulic cylinder. valve, and $\xi_{\mathrm{sv}}$ is the damping coefficient of servo valve.

If $\omega_{\mathrm{sv}}=194.78 \mathrm{rad} / \mathrm{s}$ and $\xi_{\mathrm{sv}}=0.258, \mathrm{~K}_{\mathrm{sv}}=0.05$, then the transfer function of Servo Valve is illustrated below.

$$
\mathrm{G}_{\mathrm{sv}}(\mathrm{s})=\frac{0.05}{\frac{\mathrm{s}^{2}}{194.78^{2}}+\frac{2 \times 0.258}{194.78} \mathrm{~s}+1}
$$

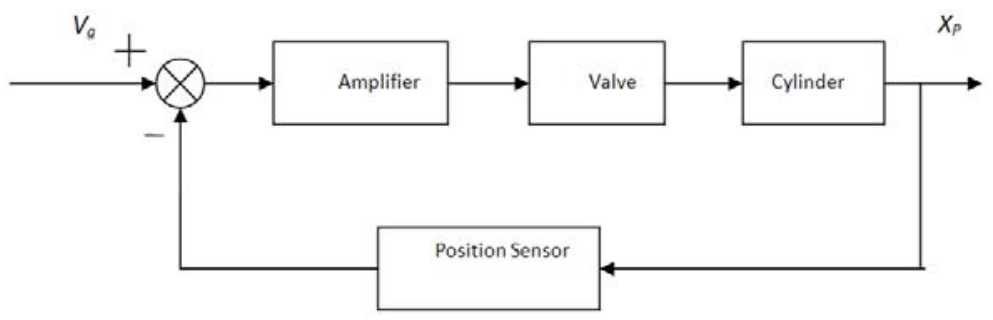

Figure 5. Screw-down System

The following shows functions of components of the screw-down system.

\section{(1) Servo Amplifier}

$$
\mathrm{G}_{\mathrm{amp}}(\mathrm{s})=\mathrm{K}_{\mathrm{a}} \mathrm{G}_{\mathrm{c}}(\mathrm{s})=0.146 \cdot \frac{0.2 \mathrm{~s}+1}{2.4 \mathrm{~s}+1}
$$

Here, $\mathrm{G}_{\text {amp }}(\mathrm{s})$ is the amplifier's transfer function

$\mathrm{K}_{\mathrm{a}}$-the proportional gain of amplifier

$\mathrm{G}_{\mathrm{c}}(\mathrm{s})$-the transfer function of correction element

(2) Servo Valve

$$
\mathrm{G}_{\mathrm{sv}}(\mathrm{s})=\frac{\mathrm{K}_{\mathrm{sv}}}{\frac{\mathrm{s}^{2}}{\omega_{\mathrm{sv}}^{2}}+\frac{2 \xi_{\mathrm{sv}}}{\omega_{\mathrm{sv}}} \mathrm{s}+1}
$$

Here, $G_{s v}(s)$ is the transfer function of servo valve, $\omega_{\mathrm{sv}}$ is the natural frequency of servo
Hydraulic Cylinder:

$$
\mathrm{G}_{\text {cyl }}(\mathrm{s})=\frac{39.32}{\mathrm{~s}\left(\frac{\mathrm{s}^{2}}{182.7^{2}}+\frac{2 \times 0.35}{182.7} \mathrm{~s}+1\right)}
$$

Position Sensor: $G_{p}(s)=K_{p}=100$

To sum up, the transfer function of the hydraulic screw-down servo system is showed below.

$$
\mathrm{G}_{\text {screw-down }}(\mathrm{s})=\mathrm{G}_{\mathrm{amp}}(\mathrm{s}) \cdot \mathrm{G}_{\mathrm{sv}}(\mathrm{s}) \cdot \mathrm{G}_{\mathrm{cyl}}(\mathrm{s}) \cdot \mathrm{G}_{\mathrm{p}}(\mathrm{s})
$$

Use the Simulink tool of the Matlab to simulate the hydraulic screw-down system. The simulation result is shown in Figure 6. From this figure, we can conclude that there is a constant time delay in the system. However, the whole system is stable.

With the control objectives of hydraulic screwdown servo system mentioned above, the AGC

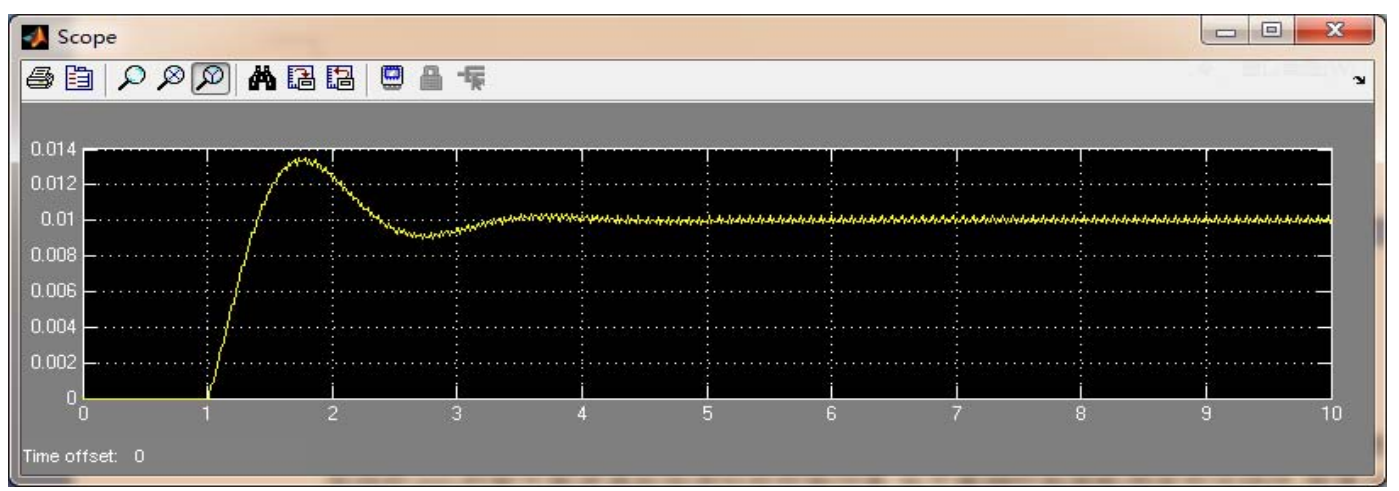

Figure 6. Simulation Results of the Screw-down System 


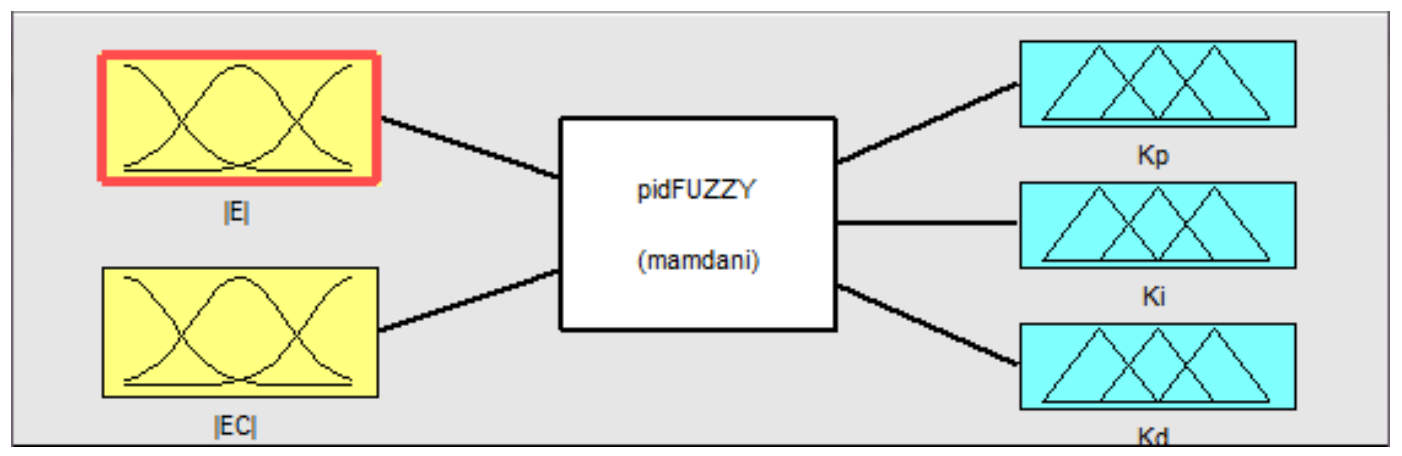

Figure 7. Fuzzy Inference Relationship

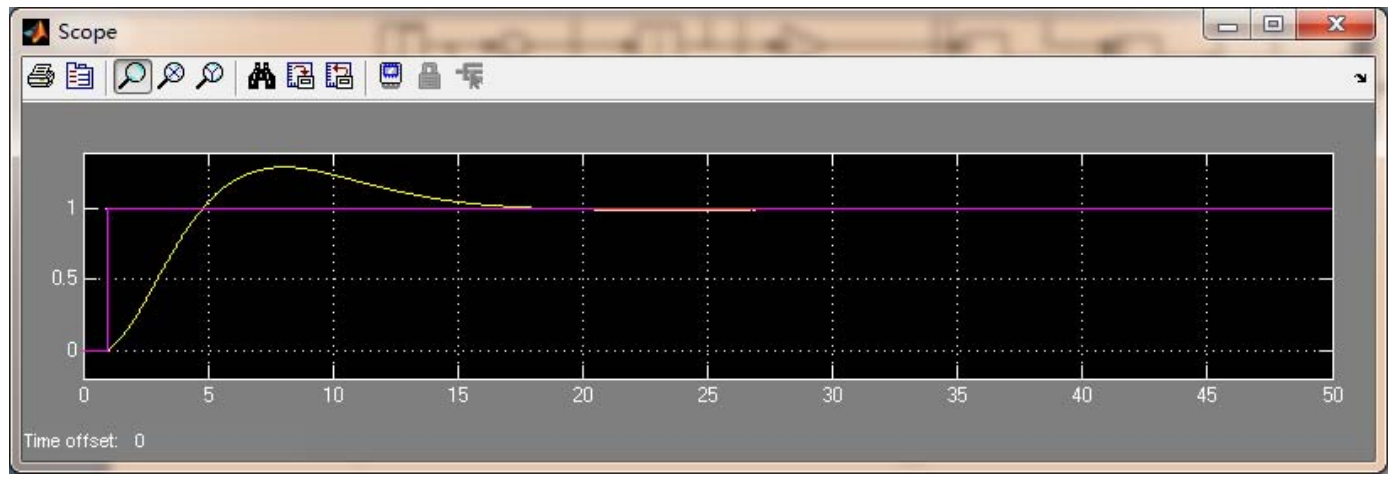

Figure 8. Simulation results of AGC System Based on Fuzzy PID

system with fuzzy PID controller is built. According to Figure 7, a clear fuzzy inference relationship between input variables $(|\mathrm{E}|,|\mathrm{EC}|)$ and output variables (Kp, Ki, Kd).

The simulation results are shown in Figure 8. Compared to Figure 6, the response is smoother and the system's anti-interference ability is improved [25]. Besides, the over shoot is also smaller. And the methods of gauge control based on ARM and fuzzy PI algorithm get great effect in the AGC hydraulic computer control system [26].

\section{Conclusions}

We designed an intelligent gauge control system with ARM chips and fuzzy PI controller. Our system is more useful to keep the stability of this control system against the thickness errors than some traditional control systems. Besides, our system depends less on some accurate mathematics models of the control objects than the traditional ones. We will improve this gauge control system with new advanced intelligent techniques, such as the immune PID control, machine learning etc.

\section{Nomenclature}

$G_{p}$ - Position Command from Computer Control Unit

$O_{p}$ - Actual Position of Hydraulic Oil Cylinder

PI - Proportional and Integral

$G_{g}$ - Input Gauge of sheet strips

$G_{o}$ - Output Gauge of sheet strips

Gc1 - thickness controller

Gc2 - position controller

ACA - Automatic Compensation Adjuster

APA - Automatic Position Adjuster

ATA - Automatic Thickness Adjuster

E - Error Signal

EC - the differential of error signal

$K_{p}$ - Proportional Factor

$K_{i}$ - Integral Factor

$|E|$ - the Absolute Value of Error Signal

$K_{d}$ - Differential Factor 
$k_{\psi}$ - Quantized Coefficients

$u(x)$ - Membership Function

$G_{\text {amp }}$ - the Transfer Function of Hydraulic

Servo Amplifier

$\mathrm{G}_{\mathrm{sv}}$ - the Transfer Function of Hydraulic Servo Valve

$\mathrm{G}_{\text {cyl }}$-the Transfer Function of Hydraulic Cylinder

$\mathrm{G}_{\text {screw-down }}$ - the Transfer Function of Hydraulic

Screw-Down Mechanism

\section{Acknowledgements}

The work was supported in part by grants from the National Natural Science Foundation of China (61271114), the Shanghai postgraduate education creative plan (SHGS-KC-2012OO3), the Natural Science Foundation of Shanghai (08ZR1400400, 11ZR1401300), and the Shanghai Educational Development Foundation (2007CG42, 12CG35).

\section{REFERENCES}

1. MASON, J. O. III, S. R. GUPTA, C. J. COMPTON, Comparison of Hemorrhagic Complications of Warfarin and Clopidogrel Bisulfate in 25-Gauge Vitrectomy versus a Control Group, Ophthalmology, vol. 118, no. 3, 2011, pp. 543-547.

2. SCHOENE, T., J. ILLIGNER, P. MANURUNG, GPS-controlled Tide Gauges in Indonesia - a German Contribution to Indonesia's Tsunami Early Warning System, Natural Hazards and Earth System Sciences, vol. 11, no. 3, 2011, pp. 731-740.

3. MURAKAMI, A., M. NAKAYAMA, Y. MAEDA, Tension Reference Optimization in Automatic Gauge and Tension Control for a Tandem Cold Mill, Tetsu To Hagane - Journal of the Iron and Steel Institute of Japan, vol. 96, no. 10, 2010, pp. 601-607.

4. NIKOLSKII, A. A., V. V. KOROLEV, D. Y. MURINETS, Features in the Control of The Cross-sectional Profile of Pistons on Out-of-Round Gauges with Model Rotation of the Spindle, Measurement Techniques, vol. 53, no. 2, 2010, pp. 156-165.

5. WANG, Q. S., Active Buckling Control of Beams using Piezoelectric Actuators and Strain Gauge Sensors, Smart Materials \& Structures, vol. 19, no. 6, 2010.

6. DONG, M., C. LIU, G. Y. LI, Robust Fault Diagnosis Based on Nonlinear Model of Hydraulic Gauge Control System on Rolling Mill, IEEE Transactions on Control Systems Technology, vol. 18, no. 2, 2010, pp. 510-515.

7. ROMAN, N., E. CEANGA, I. BIVOL, Adaptive Automatic Gauge Control of a Cold Strip Rolling Process, Advances in Electrical and Computer Engineering, vol. 10, no. 1, 2010, pp. 7-17.

8. ZHANG, D. H., H. ZHANG, T. SUN, Monitor Automatic Gauge Control Strategy with a Smith Predictor for Steel Strip Rolling, Journal of University of Science and Technology Beijing, vol. 15, no. 6, 2008, pp. 827-832.

9. LINGHU, K. Z., A. R. HE, Q. YANG, Dynamic Decoupling for Combined Shape and Gauge Control System in Wide Strip Rolling Process, Journal of Iron and Steel Research International, vol. 15, no. 2, 2008, pp. 28-31.

10. YANG, B. H., W. D. YANG, L. G. CHEN, Dynamic Optimization of Feedforward Automatic Gauge Control based on Extended Kalman Filter, Journal of Iron and Steel Research International, vol. 15, no. 2, 2008, pp. 39-42.

11. GONG, T., L. QI, Novel ARM-Based Gauge Control System with Fuzzy PI Controller, International Journal of Multimedia and Ubiquitous Engineering, vol. 7, no. 2, 2012, pp. 527-532.

12. ZHANG, Y. C., H. Q. LIANG, X. J. HU, EMC Study of an ARM-based Electronic Control Unit for High Power DC/DC Converter, IEEE Vehicle Power and Propulsion Conference, 2008.

13. QI, L., T. GONG, Gauge Control System Based on ARM and Fuzzy PI Controller, Chinese patent, 2011. 
14. CHAIYATHAM, T., I. NGAMROO, A Bee Colony Optimization Based-Fuzzy Logic-Pid Control Design of Electrolyzer For Microgrid Stabilization, International Journal of Innovative Computing Information and Control, vol. 8, no. 9, 2012, pp. 6049-6066.

15. DINH, Q. T., Q. T. TRUONG, K. K. AHN, , Development of a Novel Linear Magnetic Actuator with Trajectory Control based on an Online Tuning Fuzzy PID Controller, International Journal of Precision Engineering and Manufacturing, vol. 13, no. 8, 2012, pp. 1403-1411.

16. PARIS, B., J. EYNARD, S. GRIEU, Hybrid PID-fuzzy Control Scheme for Managing Energy Resources in Buildings, Applied Soft Computing, vol. 11, no. 8, 2011, pp. 5068-5080.

17. DINH, Q. T., K. K. AHN, Parallel Control for Electro-Hydraulic Load Simulator Using Online Self Tuning Fuzzy PID Technique, Asian Journal of Control, vol. 13, no. 4, 2011, pp. 522-541.

18. TRUONG, D. Q., K. K. AHN, Force Control for Press Machines using an Online Smart Tuning Fuzzy PID based on a Robust Extended Kalman Filter, Expert Systems with Applications, vol. 38, no. 5, 2011, pp. 5879-5894.

19. REN, X. Y., F. S. DU, H. G. HUANG, Application of Improved Fuzzy Immune PID Controller to Bending Control System, Journal of Iron and Steel Research International, vol. 18, no. 3, 2011, pp. 28-33.
20. JAHEDI, G., M. M. ARDEHALI, Genetic Algorithm-based Fuzzy-PID Control Methodologies for Enhancement of Energy Efficiency of a Dynamic Energy System, Energy Conversion and Management, vol. 52, no. 1, 2011, pp. 725-732.

21. MOHAN, B. M., Fuzzy PID Control via Modified Takagi-Sugeno Rules, Intelligent Automation and Soft Computing, vol. 17, no. 2, 2011, pp. 165-174.

22. PAN, I., S. DAS, A. GUPTA, Tuning of an Optimal Fuzzy PID Controller with Stochastic Algorithms for Networked Control Systems with Random Time Delay, ISA Transactions, vol. 50, no. 1 , 2011, pp. 28-36.

23. CETIN, S., A. V. AKKAYA, Simulation and Hybrid Fuzzy-PID Control for Positioning of a Hydraulic System, Nonlinear Dynamics, vol. 61, no. 3, 2010, pp. 465-476.

24. WANG, W., Z. M. QIU, Analysis of Characteristics of Depressing System of Rolling Mill Hydraulic Pressure, Journal of Changsha University, vol. 24, no. 2, 2010, pp. 42-43.

25. SUN, M. H., Y. Q. WANG, W. ZHANG, Research on Cascade Predictive Control in Hydraulic AGC of Cold Rolling Mill, Proceedings of 2007 2nd IEEE Conference on Industrial Electronics and Applications, 2007.

26. ALFARO, V. M., R. VILANOVA, Performance/Robustness Trade-off Design Frame-work for 2DoF PI Controllers, Studies in Informatics and Control, vol. 21, no. 1, 2012, pp. 75-83. 